\title{
Clinical utility of $3 \%$ diquafosol ophthalmic solution in the treatment of dry eyes
}

This article was published in the following Dove Press journal:

Clinical Ophthalmology

15 May 2015

Number of times this article has been viewed

\author{
Shizuka Koh \\ Department of Ophthalmology, \\ Osaka University Graduate School \\ of Medicine, Suita, Osaka, Japan
}

\begin{abstract}
Diquafosol is a drug used for dry eye treatment with a novel mechanism of action. It stimulates the secretion of tear fluid and mucin on the ocular surface, thus enabling us to selectively treat the tear film layer, playing an important role in the establishment of the concept of "Tear Film Oriented Therapy (TFOT)", an effective therapeutic approach to dry eye in Japan. The 3\% diquafosol ophthalmic solution has been widely used for the treatment of dry eye in clinical practice, and it is currently available in Japan and South Korea. This review provides an overview of the clinical utility of $3 \%$ diquafosol ophthalmic solution, focusing on the results of clinical studies on various types of dry eye, including aqueous-deficient dry eye, short tear film breakup time-type dry eye, and post dry eye after laser in situ keratomileusis. It also introduces the additive effect of diquafosol on sodium hyaluronate monotherapy for dry eye, and the effect of $3 \%$ diquafosol ophthalmic solution for dry eye-related conditions. Additionally, it summarizes the ocular effects of diquafosol in healthy human eyes. Lastly, the importance of improving tear film stability in dry eye treatment, as well as general advances in dry eye treatments, are described.
\end{abstract}

Keywords: diquafosol, dry eye, mucin secretion, fluid secretion, ocular surface, vision

\section{Introduction}

Dry eye is one of the most common reasons for patient visits to eye clinics, as it affects $5 \%-30 \%$ of the population worldwide. ${ }^{1,2}$ The 2007 Report of the International Dry Eye WorkShop (DEWS) has defined dry eye as follows: dry eye is a multifactorial disease of the tears and ocular surface that results in symptoms of discomfort, visual disturbance, and tear film instability, with potential damage to the ocular surface. ${ }^{3}$ Although the available treatments vary among the numerous counties and regions, the DEWS report suggested selecting treatments for each severity level of dry eye from a menu of therapies deemed effective in that specific area. ${ }^{4}$ In general, artificial tears or lubricating drops are often used for symptom relief in mild to moderate dry eye. Tear retention agents or anti-inflammatory agents are usually used concurrently.

In Japan, cyclosporine A ophthalmic solution is not an approved treatment for dry eye. Sodium hyaluronate ophthalmic solutions have been the primary products used to treat dry eye, in conjunction with preservative-free artificial ophthalmic solutions, for many years. Two new topical pharmacologic agents have recently become commercially available for treating dry eye in Japan. ${ }^{5}$ The first is 3\% diquafosol ophthalmic solution (Diquas, ophthalmic solution 3\%; Santen Pharmaceutical Co. Ltd, Osaka, Japan), which stimulates aqueous and mucous secretion directly on the ocular surface. The other is $2 \%$ rebamipide ophthalmic suspension (Mucosta ophthalmic suspension UD2\%; Otsuka Pharmaceutical, Co., Ltd, Tokyo, Japan), which stimulates mucous secretion. These new eye drops have enabled us to selectively treat the tear film layer 
and increase its stability. Decreased tear film stability has been emphasized as the core mechanism of dry eye in Japan; therefore, dry eye has been treated from the perspective of improving the tear film stability. Thanks to the arrival of ophthalmic solutions that stimulate the secretion of mucin and water, we are now entering a new era of a layer-by-layer ocular surface-based diagnosis and treatment of dry eye. Recently, the Dry Eye Society of Japan advocated "Tear Film Oriented Therapy (TFOT)" as an effective therapeutic approach to dry eye (Figure 1). ${ }^{6}$ Based on TFOT, we expect that each layer of the ocular surface may be targeted by a selective topical therapy, thereby further stabilizing the tear film. ${ }^{6}$

3\% Diquafosol ophthalmic solution was launched at the end of 2010 as a drug for the treatment of dry eye with a novel mechanism of action involving the stimulation of tear and mucin secretion. ${ }^{7}$ Diquafosol has been widely used to treat dry eye in clinical practice, and is currently approved in Japan and South Korea for dry eye treatment. It is a $\mathrm{P} 2 \mathrm{Y}_{2}$ purinergic receptor agonist that activates $\mathrm{P}_{2} \mathrm{Y}_{2}$ receptors on the ocular surface. Diquafosol stimulates both fluid secretion from the conjunctival epithelial cells and mucin secretion from the conjunctival goblet cells directly on the ocular surface by an interaction with the $\mathrm{P}_{2} \mathrm{Y}_{2}$ receptors. Diquafosol may not act on the lacrimal glands directly; it did not stimulate protein secretion from isolated rabbit lacrimal glands. ${ }^{8}$ On the other hand, it is known that diquafosol not only stimulates mucin secretion from the conjunctival goblet cells, but it also upregulates the expression of membrane-binding mucin genes in corneal epithelial cells. ${ }^{9}$ Thus, diquafosol enhances the stabilization of the tear film and hydration of the ocular surface, independent of tear fluid secretion from the lacrimal glands. ${ }^{10-13}$ According to studies of animal models, diquafosol promotes tear fluid and mucin secretion leading to the improvement of corneal epithelial barrier function, and it also suppresses corneal epithelial damage induced by desiccation of the ocular surface. ${ }^{13,14}$

This article reviews the clinical therapeutic effects of $3 \%$ diquafosol ophthalmic solution in patients with dry eye, as well as summarizes its effects in healthy eyes.

\section{Ocular effects in healthy eyes}

Several studies have evaluated the ocular effects of using $3 \%$ diquafosol ophthalmic solution in healthy human eyes,
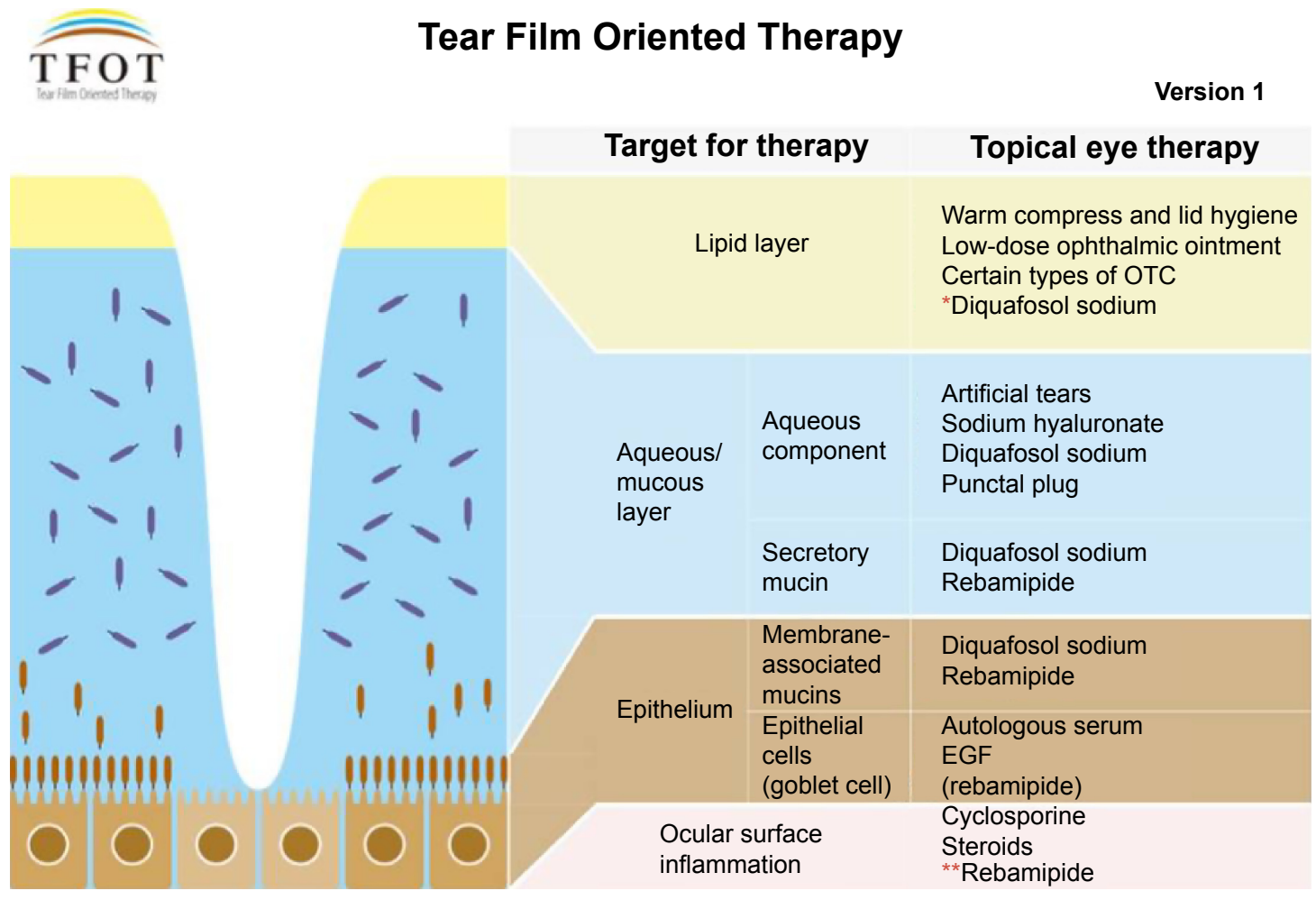

Figure I Concept diagram of TFOT.

Notes: Current topical dry eye therapy options that contribute to the treatment of each layer of the ocular surface are demonstrated. *Diquafosol sodium may increase the function of the tear film lipid layer by promoting spreading of the lipid layer through lipid and tear fluid secretion. **Rebamipide may suppress the inflammation of the ocular surface in dry eye by its anti-inflammatory action. Copyright @ D Dry Eye Society. Reproduced from TFOT (Tear Film Oriented Therapy) [webpage on the Internet]. Tokyo: Dry Eye Society of Japan. Available from: http://www.dryeye.ne.jp/en/tfot/index.html. Accessed May 7, $2015 .^{41}$

Abbreviations: TFOT, Tear Film Oriented Therapy; OTC, over-the-counter; EGF, epidermal growth factor. 
which should be helpful in the use of diquafosol for dry eyes in clinical practice. ${ }^{15-17}$ Currently, an increase of the ocular surface fluid volume, ${ }^{15}$ an increase in the concentration of mucin-like substance, ${ }^{16}$ and the short-term effects on optical quality ${ }^{17}$ induced by diquafosol ophthalmic solution have been reported.

A significant increase of the ocular surface tear volume was observed after a single topical instillation of 3\% diquafosol ophthalmic solution in healthy human eyes. ${ }^{15}$ Using the reflective meniscometry technique, the radius of curvature of the lower tear meniscus was measured noninvasively. While there was no significant change with instillation of artificial tears, instillation of $3 \%$ diquafosol ophthalmic solution increased tear fluid on the ocular surface for up to 30 minutes. ${ }^{15}$

The collected tear samples after the instillation of $3 \%$ diquafosol ophthalmic solution showed a transient but significant increase in sialic acid concentration in healthy human subjects. ${ }^{16}$ Because sialic acid is considered a good marker for monitoring mucin in biological samples, diquafosol could possibly stimulate the secretion of mucin from the ocular tissues of human eyes.

The short-term effects of viscosity and suspensibility of dry eye drop instillation on optical quality were investigated by measurement of ocular higher-order aberrations (HOAs) and ocular forward light scattering. ${ }^{17}$ Although an increase in HOAs was observed 1 minute after instillation of $3 \%$ diquafosol ophthalmic solution when compared to baseline, the increase was minimal when compared to the instillation of highly viscous $0.3 \%$ sodium hyaluronate ophthalmic solution. No significant changes in ocular forward light scattering were seen with the instillation of $3 \%$ diquafosol ophthalmic solution, although $2 \%$ rebamipide ophthalmic suspension was found to have a significant increase from baseline in this parameter. Since 3\% diquafosol ophthalmic solution is functionally free from viscosity and suspensibility after instillation, and given that no remarkable short-term effect of instillation is demonstrated, this suggests that patients are more likely to comply with treatment because it will not obscure their vision.

\section{Therapeutic efficacy in clinical trials and clinical studies}

A summary of the clinical trials and clinical studies described in the remaining sections is demonstrated in Table 1.

\section{Clinical trials}

There are three randomized, double-blind, multicenter, parallel-group clinical trials. ${ }^{18-20}$ In this section, we focus on a placebo-controlled study that was performed mainly to evaluate the efficacy and proper dosage (a Phase II study) of sodium hyaluronate ophthalmic solution, ${ }^{19}$ and on an active-controlled study against $0.1 \%$ sodium hyaluronate ophthalmic solution (a Phase III study). ${ }^{20}$ Improvement in corneal epithelial damage was chosen as the primary endpoint for these studies. ${ }^{19,20}$ The fluorescein (FL) staining score and the rose bengal (RB) staining score were used to evaluate corneal epithelial damage and conjunctival epithelial damage, respectively. In these studies, one drop of ophthalmic solution was instilled six times daily for 4 weeks or 6 weeks, for the Phase III and Phase II studies, respectively. ${ }^{19,20}$ In the Phase II dose-finding study, ${ }^{19}$ which compared $1 \%$ and $3 \%$ diquafosol ophthalmic solutions, the efficacy of the solutions against the placebo was determined for both doses in terms of FL and RB scores. At week 6, a significant decrease in the FL and RB scores was observed for the $1 \%$ and $3 \%$ diquafosol groups when compared with the placebo group. In the FL score, dose dependency was also confirmed, suggesting that $3 \%$ was considered more effective than the $1 \%$ solution.

In the Phase III study, the FL scores were significantly improved from baseline at weeks 2 and 4 , with both 3\% diquafosol ophthalmic solution and $0.1 \%$ hyaluronate ophthalmic solution. Moreover, the $3 \%$ diquafosol ophthalmic solution was shown to be noninferior to the $0.1 \%$ hyaluronate ophthalmic solution at week 4 for this endpoint. A significant decrease in the RB scores was also observed for both groups at weeks 2 and 4 compared with baseline. However, the improvement from baseline to week 4 in the RB score was significantly greater with $3 \%$ diquafosol than with $0.1 \%$ hyaluronate ophthalmic solution, which showed an increased efficacy in lowering the RB score for patients with dry eye. ${ }^{20}$

A recent large, multicountry, randomized clinical trial conducted in the People's Republic of China and Singapore has reported the efficacy and safety of 3\% diquafosol ophthalmic solution and compared them with those of $0.1 \%$ hyaluronate ophthalmic solution. ${ }^{21}$ One drop of either ophthalmic solution was instilled six times daily for 4 weeks. In the diquafosol group, as compared with the hyaluronate group, changes in FL score were noninferior and changes in RB score were superior at week 4 . Both groups improved in tear film breakup time.

\section{Clinical studies}

Aqueous-deficient dry eye

In a study evaluating the long-term efficacy of diquafosol ophthalmic solution, ${ }^{22}$ patients received one drop of $3 \%$ 


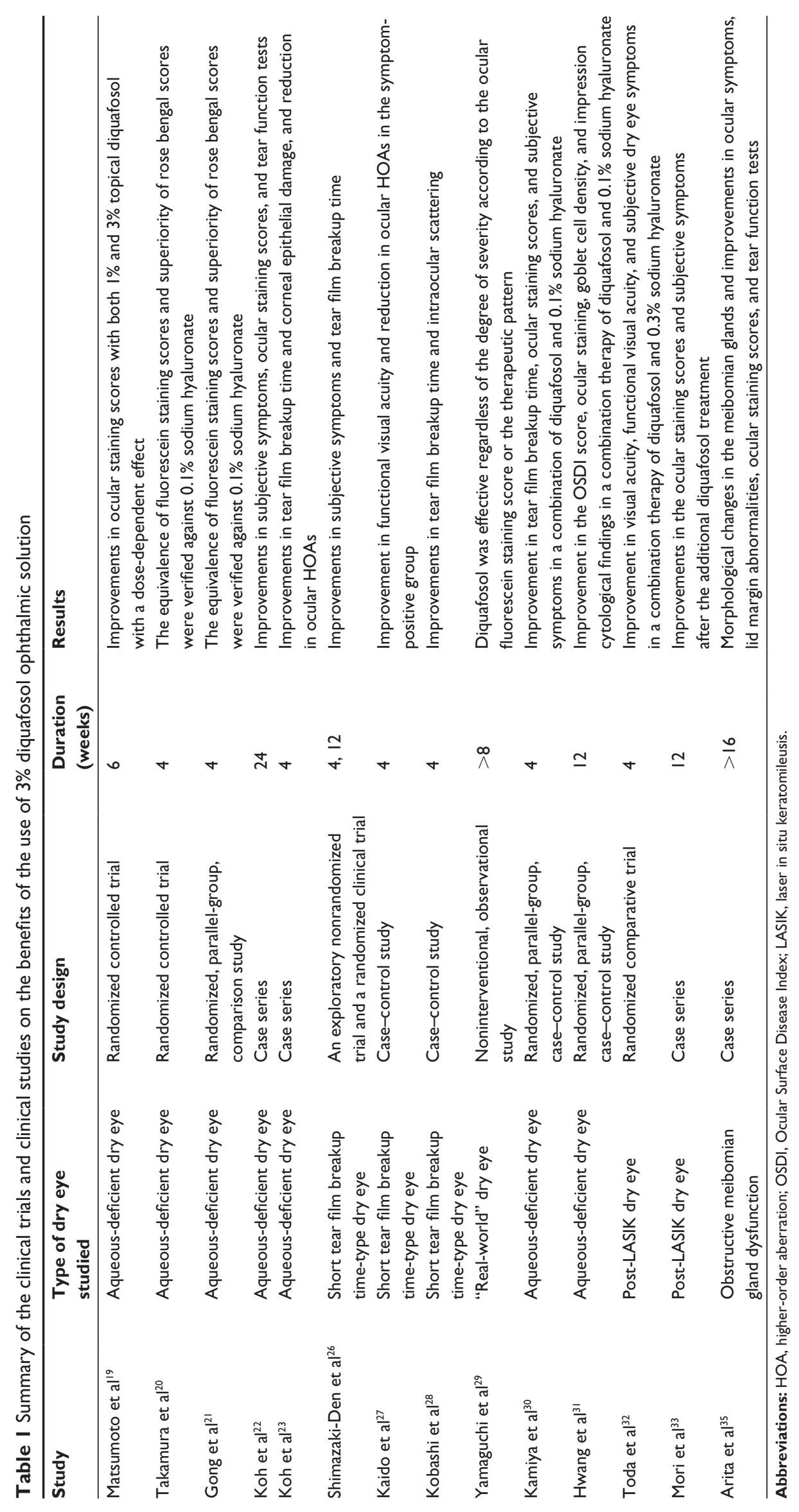


diquafosol ophthalmic solution six times daily for 6 months. Prolonged use of diquafosol ophthalmic solution for 6 months produced significant improvement both subjectively (dry eye symptom score) and objectively (ocular staining score and tear function tests).

In a subsequent study by the same group, ${ }^{23}$ the short-term (after 15 minutes of instillation) and long-term (after 4 weeks of six times daily administration) effects of diquafosol ophthalmic solution on optical quality were evaluated in aqueous-deficient dry eye. Ocular HOAs were measured with a wavefront sensor before and 15 minutes after diquafosol instillation at the baseline visit and at 4 weeks after treatment initiation. No significant change in HOAs was observed as a short-term effect of a single-drop instillation of diquafosol. However, the long-term use of diquafosol to treat dry eye reduced HOAs, as well as improved tear film stability and corneal epithelial damage.

As the majority of the patients in these studies had Sjögren's syndrome, ${ }^{22,23} 3 \%$ diquafosol may be effective for mild to moderate patients with Sjögren's syndrome.

\section{Short tear film breakup time-type dry eye}

Clinically, the short tear film breakup time-type dry eye has been reported to be associated with a shorter tear film breakup time and dry eye symptoms without ocular surface damage and tear deficiency. ${ }^{24,25}$ The efficacy of 3\% diquafosol ophthalmic solution in short tear film breakup time-type dry eye was examined in a few studies. ${ }^{26-28}$ One drop of 3\% diquafosol ophthalmic solution was administered six times daily in each study.

An exploratory nonrandomized trial ${ }^{26}$ showed significant improvements in subjective symptoms and tear film breakup time at both 1 month and 3 months after treatment with $3 \%$ diquafosol ophthalmic solution. In a 4-week randomized, clinical study comparing 3\% diquafosol ophthalmic solution with artificial tears, ${ }^{26}$ significant improvements in dry eye symptoms were noted in the diquafosol group, but not in the artificial tear group at week 2 . Tear film breakup time was significantly prolonged in the diquafosol group at week 4 .

In a nonrandomized study, ${ }^{27}$ patients with short tear film breakup times were classified based on the presence of dry eye symptoms. Visual function, as well as tear film breakup time, were evaluated at 1 month. After the administration of $3 \%$ diquafosol ophthalmic solution, the tear film breakup time was significantly increased from baseline in the symptomnegative group, but not in the symptom-positive group. In contrast, significant improvements in functional visual acuity and ocular HOAs were observed in the symptompositive group, but not in the symptom-negative group.
According to the recent report investigating the short-term effects on intraocular scattering, ${ }^{28} 3 \%$ diquafosol ophthalmic solution generated improvements not only in tear film breakup time, but also in intraocular scattering measurements. These measures deteriorate significantly with time in patients with short tear film breakup time-type dry eye, indicating that diquafosol is also effective for improving the optical quality of the eye.

\section{Patients with general or "real-world" dry eye}

This multicenter, prospective, noninterventional observational study ${ }^{29}$ evaluated the efficacy and safety of $3 \%$ diquafosol ophthalmic solution from over 3,000 dry eye patients. It included "real-world" dry eye patients who were excluded from clinical trials because of limitations such as age, contact lens use, and the use of eye drops other than diquafosol. The study demonstrated that the six times daily administration of 3\% diquafosol ophthalmic solution was effective regardless of the severity of dry eye based on the ocular FL staining score, or on a therapeutic pattern. A total of $76.0 \%$ of the enrolled patients responded that their condition had improved.

\section{The additive effect of diquafosol on sodium hyaluronate monotherapy}

An option for adding 3\% diquafosol ophthalmic solution in combination with $0.1 \%$ sodium hyaluronate ophthalmic solution has been suggested for dry eye cases where sodium hyaluronate monotherapy is insufficient..$^{30}$ Each eye was randomly assigned to one of the two regimens in each patient: $3 \%$ diquafosol ophthalmic solution plus $0.1 \%$ sodium hyaluronate ophthalmic solution in one eye; and $0.1 \%$ sodium hyaluronate alone in the other. The patients applied one drop of the ophthalmic solution six times daily. After 2 weeks and 4 weeks of treatment with diquafosol ophthalmic solution, significant improvements in tear film breakup time and ocular staining scores were observed. In terms of subjective symptoms, significant improvements for dry eye sensation, pain, and foreign body sensations were observed with the combination of $3 \%$ diquafosol ophthalmic solution and $0.1 \%$ sodium hyaluronate ophthalmic solutions.

A study from South Korea, ${ }^{31}$ where $3 \%$ diquafosol ophthalmic solution was launched in 2013, showed the beneficial effect of the combination therapy with preservative-free $0.1 \%$ sodium hyaluronate ophthalmic solution and 3\% diquafosol ophthalmic solution. Dry eye patients were randomly assigned to one of three treatment groups: preserved $0.1 \%$ sodium hyaluronate; $3 \%$ diquafosol; and a combination of $3 \%$ 
diquafosol and preservative-free $0.1 \%$ sodium hyaluronate for 3 months. Patients applied one drop of the ophthalmic solution four times daily. The combination therapy with 3\% diquafosol and preservative-free $0.1 \%$ sodium hyaluronate significantly improved the Ocular Surface Disease Index score, ocular staining, goblet cell density, and impression cytological findings more so than either hyaluronate or diquafosol monotherapies.

\section{Dry eye after laser in situ keratomileusis (LASIK)}

The efficacy of $3 \%$ diquafosol ophthalmic solution in patients with dry eye following LASIK was examined in the following two studies. ${ }^{32,33}$ In one study, ${ }^{32}$ post-LASIK dry eye patients were randomly assigned to one of four treatment groups: artificial tears; $0.3 \%$ sodium hyaluronate; $3 \%$ diquafosol; or a combination of $3 \%$ diquafosol and $0.3 \%$ sodium hyaluronate. Patients applied one drop of the ophthalmic solution six times daily. Distance and near uncorrected visual acuity improved after the combination therapy more so than with $0.3 \%$ hyaluronate or $3 \%$ diquafosol monotherapies. Distance functional visual acuity improved significantly, but only in the combination group 1 month after LASIK. Subjective dry eye symptoms in the combination group improved significantly when compared with those in the other groups 1 week after surgery.

Longer-term treatment with 3\% diquafosol ophthalmic solution was evaluated in persistent dry eye after LASIK. ${ }^{33}$ One drop of diquafosol ophthalmic solution 3\% was administered six times daily. The ocular staining scores significantly improved over 12 weeks; however, the best-corrected visual acuity and tear secretion did not change. In terms of subjective symptoms, significant improvements for fatigue, dryness, grittiness, discomfort, difficulty in reading, and discomfort within the area of dryness were observed after the additional diquafosol treatment.

Both studies suggest that for LASIK-associated dry eye, the additional treatment of $3 \%$ diquafosol ophthalmic solution would be more effective than with the conventional therapy using artificial tears or sodium hyaluronate. ${ }^{32,33}$

\section{Obstructive meibomian gland dysfunction (MGD)}

$\mathrm{P}_{2} \mathrm{Y}_{2}$ receptors are also known to exist in the meibomian glands. ${ }^{34}$ Obstructive MGD is a major cause of lipid layer deficiency and evaporative dry eye, and it may result in unstable tear film.

A study performing quantitative image analysis of meibomian gland morphology, as well as tear film parameters, showed the beneficial effect of diquafosol in patients with
MGD. ${ }^{35}$ More than 4 months of diquafosol therapy (four times daily administration) significantly improved ocular symptoms, lid margin abnormalities, ocular staining scores, and tear function tests. The mean ratio of the meibomian gland area imaged with noncontact meibography significantly increased after treatment. Diquafosol may be one of the treatment options for MGD in which conventional therapies, such as warm compresses, lid hygiene, and artificial tear eye drops or systemic medications, are often unsatisfactory or poorly tolerated. ${ }^{36}$

\section{Patients with dry eye-related conditions}

The efficacy of 3\% diquafosol ophthalmic solution has also been reported in dry eye-related conditions, where patients have abnormal tear film dynamics or where their symptoms are temporary. ${ }^{37,38}$ The effect of pretreatment with $3 \%$ diquafosol ophthalmic solution on intraoperative corneal wetting during cataract surgery has been reported. ${ }^{37}$ This study also indicates that such pretreatment prevents intraoperative iatrogenic dry eye. Since pre-existing tear film abnormalities or dry eye can affect surgical outcomes, the proper management of ocular surface diseases, such as dry eye, is important prior to performing cataract surgery or refractive surgery.

According to a recent report, a transient but significant increase in lower tear meniscus height was observed after the instillation of $3 \%$ diquafosol ophthalmic solution in eyes wearing a high water content contact lens, in which the tear meniscus height was remarkably decreased. ${ }^{38}$ Therefore, it would be expected that diquafosol ophthalmic solution could work as solution for contact lens-related dry eye.

\section{Safety of diquafosol}

Of the 655 subjects who were enrolled in clinical trials and received diquafosol, adverse drug reactions were reported in 155 subjects $(23.7 \%) .^{7,18-20}$ Major adverse drug reactions included eye irritation (6.7\%), eye discharge (4.7\%), conjunctival injection $(3.7 \%)$, eye pain $(2.7 \%)$, eye pruritus $(2.4 \%)$, foreign body sensation (2.1\%), and eye discomfort $(1.1 \%){ }^{7}$ The majority of adverse reactions were of mild severity, and no serious treatment-related adverse events were reported. According to the results of the multicenter clinical study for "real-world" dry eyes, ${ }^{29}$ adverse reactions were observed in $6.3 \%$ of patients, and the major adverse reactions were eye discharge, eye irritation, and eye pain. According to the results of a 6-month clinical study, ${ }^{22}$ the good tolerability of diquafosol ophthalmic solution $3 \%$ was maintained in the longer term. 


\section{Conclusion}

This review provides an overview of 3\% diquafosol ophthalmic solution, mainly focusing on its clinical utility obtained from clinical studies. The clinical efficacy of 3\% diquafosol ophthalmic solution has been confirmed for dry eye, including aqueous-deficient dry eye, short tear film breakup time-type dry eye, and post-LASIK dry eye. The additive effect of diquafosol on sodium hyaluronate monotherapy has also been demonstrated. Diquafosol has the potential to improve MGD, which is a chronic, symptomatic, ocular surface disease, and it often accompanies dry eye. The utility of diquafosol for treatment prior to cataract surgery or for contact lens wearers has also been described, through improving the quality or quantity of the tear film.

A recent study ${ }^{39}$ has evaluated the effect of lubricant eye drops containing eledoisin and carnitine in glaucoma patients with ocular discomfort symptoms, and it reported that lubricant eye drops that stimulate tear production and restore physiological osmolarity represent a promising strategy for dry eye syndrome in glaucoma patients. In this regard, 3\% diquafosol ophthalmic solution might be useful in patients with chronic glaucoma suffering from iatrogenic dry eye syndrome.

Based on the pathogenesis of dry eye disease, qualitative and quantitative improvements of the tear film are crucial. ${ }^{40}$ From the point of view of clinical practice, tear film instability causes dry eye symptoms, ocular surface damage, and visual disturbances. Therefore, achieving tear film stability is important for improving these symptoms or signs. As visual disturbances are noted in the definition of dry eye in the 2007 DEWS report, ${ }^{3}$ more attention has been paid to the quality of vision in dry eye. In that regard, improvement in optical quality by dry eye treatment with $3 \%$ diquafosol ophthalmic solution will be helpful to manage and maintain the quality of vision in dry eye. ${ }^{23,27,28}$

Although dry eye is a multifactorial disease of the tears and ocular surface, an increase of the availability of dry eye treatment options would enable clinicians to treat various types of dry eye more effectively in clinical practice. The successful use of diquafosol in various types of dry eye based on TFOT would be anticipated in the future.

\section{Acknowledgment}

The author wishes to thank Dr Masatsugu Nakamura (Santen Pharmaceutical Co., Ltd., Osaka, Japan) for providing assistance.

\section{Disclosure}

The author reports no conflicts of interest in this work.

\section{References}

1. The epidemiology of dry eye disease: report of the Epidemiology Subcommittee of the International Dry Eye WorkShop (2007). Ocul Surf. 2007;5(2):93-107.

2. Mizuno Y, Yamada M, Miyake Y; Dry Eye Survey Group of the National Hospital Organization of Japan. Association between clinical diagnostic tests and health-related quality of life surveys in patients with dry eye syndrome. Jpn J Ophthalmol. 2010;54(4):259-265.

3. The definition and classification of dry eye disease: report of the Definition and Classification Subcommittee of the International Dry Eye WorkShop (2007). Ocul Surf. 2007;5(2):75-92.

4. Management and therapy of dry eye disease: report of the Management and Therapy Subcommittee of the International Dry Eye WorkShop (2007). Ocul Surf. 2007;5(2):163-178.

5. Dogru M, Nakamura M, Shimazaki J, Tsubota K. Changing trends in the treatment of dry-eye disease. Expert Opin Investig Drugs. 2013 22(12):1581-1601.

6. Yokoi N. [Therapeutic guideline for dry eye: Tear Film Oriented Therapy (TFOT)]. Atarashii Ganka. 2015;32(1):9-16. Japanese.

7. Nakamura M, Imanaka T, Sakamoto A. Diquafosol ophthalmic solution for dry eye treatment. Adv Ther. 2012;29(7):579-589.

8. Takaoka-Shichijo Y, Murakami T, Nakamura M. [Stimulatory effect of diquafosol tetrasodium on tear fluid secretion in normal rabbits]. Atarashii Ganka. 2011;28(7):1029-1033. Japanese.

9. Takaoka-Shichijo Y, Nakamura M. [Stimulatory effect of diquafosol tetrasodium on the expression of membrane-binding mucin genes in cultured human corneal epithelial cells]. Atarashii Ganka. 2011;28(3): 425-429. Japanese.

10. Li Y, Kuang K, Yerxa B, Wen Q, Rosskothen H, Fischbarg J. Rabbit conjunctival epithelium transports fluid, and P2Y2(2) receptor agonists stimulate CI(-) and fluid secretion. Am J Physiol Cell Physiol. 2001; 281(2):C595-C602.

11. Jumblatt JE, Jumblatt MM. Regulation of ocular mucin secretion by P2Y2 nucleotide receptors in rabbit and human conjunctiva. Exp Eye Res. 1998;67(3):341-346.

12. Murakami T, Fujihara T, Horibe Y, Nakamura M. Diquafosol elicits increases in net Cl-transport through $\mathrm{P} 2 \mathrm{Y} 2$ receptor stimulation in rabbit conjunctiva. Ophthalmic Res. 2004;36(2):89-93.

13. Fujihara T, Murakami T, Fujita H, Nakamura M, Nakata K. Improvement of corneal barrier function by the P2Y(2) agonist INS365 in a rat dry eye model. Invest Ophthalmol Vis Sci. 2001;42(1):96-100.

14. Fujihara T, Murakami T, Nagano T, Nakamura M, Nakata K. INS365 suppresses loss of corneal epithelial integrity by secretion of mucin-like glycoprotein in a rabbit short-term dry eye model. J Ocul Pharmacol Ther. 2002;18(4):363-370.

15. Yokoi N, Kato H, Kinoshita S. Facilitation of tear fluid secretion by $3 \%$ diquafosol ophthalmic solution in normal human eyes. Am J Ophthalmol. 2014;157(1):85-92.e1.

16. Shigeyasu C, Hirano S, Akune Y, Yamada M. Diquafosol tetrasodium increases the concentration of mucin-like substances in tears of healthy human subjects. Curr Eye Res. 2014:1-6.

17. Koh S, Maeda N, Ikeda C, et al. Effect of instillation of eyedrops for dry eye on optical quality. Invest Ophthalmol Vis Sci. 2013;54(7): 4927-4933.

18. Nakamura M, Imanaka T. [New treatment. Diquafosol tetrasodium]. Jpn J Ocular Pharmacol. 2011;25(1):42-46. Japanese.

19. Matsumoto Y, Ohashi Y, Watanabe H, Tsubota K; Diquafosol Ophthalmic Solution Phase 2 Study Group. Efficacy and safety of diquafosol ophthalmic solution in patients with dry eye syndrome: a Japanese phase 2 clinical trial. Ophthalmology. 2012;119(10):1954-1960.

20. Takamura E, Tsubota K, Watanabe H, Ohashi Y; Diquafosol Ophthalmic Solution Phase 3 Study Group. A randomised, double-masked comparison study of diquafosol versus sodium hyaluronate ophthalmic solutions in dry eye patients. Br J Ophthalmol. 2012;96(10):1310-1315.

21. Gong L, Sun X, Ma Z, et al. A randomised, parallel-group comparison study of diquafosol ophthalmic solution in patients with dry eye in China and Singapore. Br J Ophthalmol. Epub 2015 Jan 28. 
22. Koh S, Ikeda C, Takai Y, Watanabe H, Maeda N, Nishida K. Long-term results of treatment with diquafosol ophthalmic solution for aqueousdeficient dry eye. Jpn J Ophthalmol. 2013;57(5):440-446.

23. Koh S, Maeda N, Ikeda C, et al. Effect of diquafosol ophthalmic solution on the optical quality of the eyes in patients with aqueous-deficient dry eye. Acta Ophthalmol. 2014;92(8):e671-e675.

24. Toda I, Shimazaki J, Tsubota K. Dry eye with only decreased tear break-up time is sometimes associated with allergic conjunctivitis. Ophthalmology. 1995;102(2):302-309.

25. Koh S, Maeda N, Hori Y, et al. Effects of suppression of blinking on quality of vision in borderline cases of evaporative dry eye. Cornea. 2008;27(3):275-278.

26. Shimazaki-Den S, Iseda H, Dogru M, Shimazaki J. Effects of diquafosol sodium eye drops on tear film stability in short BUT type of dry eye. Cornea. 2013;32(8):1120-1125.

27. Kaido M, Uchino M, Kojima T, Dogru M, Tsubota K. Effects of diquafosol tetrasodium administration on visual function in short break-up time dry eye. J Ocul Pharmacol Ther. 2013;29(6):595-603.

28. Kobashi H, Kamiya K, Igarashi A, Miyake T, Shimizu K. Intraocular scattering after instillation of diquafosol ophthalmic solution. Optom Vis Sci. Epub 2014 Dec 30.

29. Yamaguchi M, Nishijima T, Shimazaki J, et al. Clinical usefulness of diquafosol for real-world dry eye patients: a prospective, open-label, non-interventional, observational study. Adv Ther. 2014;31(11): 1169-1181.

30. Kamiya K, Nakanishi M, Ishii R, et al. Clinical evaluation of the additive effect of diquafosol tetrasodium on sodium hyaluronate monotherapy in patients with dry eye syndrome: a prospective, randomized, multicenter study. Eye (Lond). 2012;26(10):1363-1368.

31. Hwang HS, Sung YM, Lee WS, Kim EC. Additive effect of preservativefree sodium hyaluronate $0.1 \%$ in treatment of dry eye syndrome with diquafosol 3\% eye drops. Cornea. 2014;33(9):935-941.
32. Toda I, Ide T, Fukumoto T, Ichihashi Y, Tsubota K. Combination therapy with diquafosol tetrasodium and sodium hyaluronate in patients with dry eye after laser in situ keratomileusis. Am J Ophthalmol. 2014; 157(3):616-622.e1.

33. Mori Y, Nejima R, Masuda A, et al. Effect of diquafosol tetrasodium eye drop for persistent dry eye after laser in situ keratomileusis. Cornea. 2014;33(7):659-662.

34. Cowlen MS, Zhang VZ, Warnock L, Moyer CF, Peterson WM, Yerxa BR. Localization of ocular P2Y2 receptor gene expression by in situ hybridization. Exp Eye Res. 2003;77(1):77-84.

35. Arita R, Suehiro J, Haraguchi T, et al. Topical diquafosol for patients with obstructive meibomian gland dysfunction. Br J Ophthalmol. 2013;97(6):725-729.

36. Paranjpe DR, Foulks GN. Therapy for meibomian gland disease. Ophthalmol Clin North Am. 2003;16(1):37-42.

37. Miyake G, Ota I, Miyake K, Zako M, Iwaki M. Effects of topical diquafosol pretreatment on intraoperative corneal wetting. J Cataract Refract Surg. 2014;40(10):1682-1688

38. Nagahara Y, Koh S, Maeda N, Nishida K, Watanabe H. Prominent decrease of tear meniscus height with contact lens wear and efficacy of eye drop instillation. Eye Contact Lens. Epub 2015 Apr 1.

39. Nebbioso M, Evangelista M, Librando A, Plateroti AM, Pescosolido N. Iatrogenic dry eye disease: an eledoisin/carnitine and osmolyte drops study. Biomed Pharmacother. 2013;67(7):659-663.

40. Shimazaki J. [Risk factors for dry eye syndrome]. Ganka. 2011;53(11): 1553-1557. Japanese.

41. TFOT (Tear Film Oriented Therapy) [webpage on the Internet]. Tokyo: Dry Eye Society. Available from: http://www.dryeye.ne.jp/en/tfot/ index.html. Accessed May 7, 2015.
Clinical Ophthalmology

\section{Publish your work in this journal}

Clinical Ophthalmology is an international, peer-reviewed journal covering all subspecialties within ophthalmology. Key topics include: Optometry; Visual science; Pharmacology and drug therapy in eye diseases; Basic Sciences; Primary and Secondary eye care; Patient Safety and Quality of Care Improvements. This journal is indexed on

\section{Dovepress}

PubMed Central and CAS, and is the official journal of The Society of Clinical Ophthalmology (SCO). The manuscript management system is completely online and includes a very quick and fair peer-review system, which is all easy to use. Visit http://www.dovepress.com/ testimonials.php to read real quotes from published authors. 